\title{
DobradiçAs, Vertigem Epistémica E Moralidade
}

\author{
Nuno Venturinha ${ }^{1}$ \\ (Universidade Nova de Lisboa - IFILNOVA)
}

\section{Introdução}

Em vários trabalhos recentes, Duncan Pritchard (2012, 2016, 2018a, $2018 b^{2}$ ) tem procurado responder ao problema do cepticismo a partir de um enfoque wittgensteiniano, mais especificamente aquele que se encontra no Da Certeza ${ }^{3}$. Pritchard entende que o modelo epistemológico que Wittgenstein oferece nessas observações, as quais foram escritas nos dois últimos anos da sua vida, entre 1949 e 1951, fornece-nos elementos decisivos para resolvermos questões cépticas clássicas. Aquilo que Pritchard destaca é que, não tendo uma abordagem fundacionalista, a epistemologia wittgensteiniana pode prescindir de justificações que para outras perspectivas seriam determinantes. Segundo Pritchard (2012, 2016), ela baseia-se, exactamente, numa ideia de "falta de fundamentação do nosso crer" (Wittgenstein, 1974: $§ 166^{4}$ ). No entanto, tal Grundlosigkeit em epistemologia parece inadmissível, colocando enormes desafios à

1 nventurinha.ifl@fcsh.unl.pt

2 A lista de referências não pretende ser exaustiva, limitando-se a indicar os trabalhos considerados mais relevantes.

3 Não se discutirá aqui o carácter problemático que este texto tem no interior do corpus wittgensteiniano. Veja-se a esse respeito Venturinha, 2010.

4 O parágrafo na íntegra diz: "A dificuldade é compreender a falta de fundamentação do nosso crer." (Todas as traduções são da minha responsabilidade.) No original: "Die Schwierigkeit ist, die Grundlosigkeit unseres Glaubens einzusehen.” Elizabeth Anscombe traduziu o verbo einsehen por "to realize", mas é preciso ter presente que aquilo que está em causa é um "reconhecer" ou um "ver" sob a forma de um "aceitar". 
posição wittgensteiniana. O que a investigação epistemológica persegue são, justamente, "fundamentos" (Gründe) que permitam justificar o conhecimento que temos ou podemos ter nas diferentes áreas da vida humana. Não é por acaso que, tantas décadas depois de ter sido formulada, essa posição continua a ser pouco consensual. Será errado, porém, pensar-se que o projecto epistemológico wittgensteiniano consiste num total desapreço daquilo que também se poderá traduzir por "razões", a ponto de tornar esse projecto irracionalista ou, pura e simplesmente, quietista. Não sendo o meu propósito discutir aqui a questão do quietismo, que envolve diversas facetas ${ }^{5}$, contentar-me-ei em expor que qualquer pretensão de atribuir a Wittgenstein um irracionalismo em epistemologia, em virtude do seu não-fundacionalismo, passa ao lado daquilo que é mais inovador nos escritos tardios do autor. Sendo os argumentos de Pritchard fundamentais para se perceber isto, defenderei, contudo, que se pode ir ainda mais além na exploração da matriz epistemológica wittgensteiniana.

$\mathrm{O}$ texto divide-se em três secções. Começarei por expor o ideário de uma "epistemologia-dobradiça" (hinge epistemology) recorrendo a passagens do Da Certeza e introduzindo exemplos no âmbito dos quais se tornará patente o carácter eminentemente empírico das hinge propositions. Em seguida analisarei a relevância da noção de "compromissos-dobradiça a-racionais" (arational hinge commitments) avançada por Pritchard e debaterei a ideia de "compromissos-dobradiça superlativos" (über hinge commitments), os quais se constituem em "proposições-dobradiça superlativas" (über hinge propositions), por diferença face aos "compromissos-dobradiça pessoais" e às "proposições-dobradiça pessoais" que deles derivam, enquanto non-über. Na terceira secção introduzirei o problema do conhecimento do nosso conhecimento, trazendo para a discussão temas da filosofia de Timothy Williamson, designadamente o da "inexactidão" do nosso conhecer, e procurarei compreender outro par de noções que pertencem ao vocabulário epistemológico de Pritchard: as de "compromissos-dobradiça anticépticos" e "proposições-dobradiça anticépticas". No âmbito da conclusão aplicarei os resultados obtidos ao problema que resulta da distinção feita por Pritchard entre "angústia epistémica" (epistemic angst) e "vertigem epistémica" (epistemic vertigo), nomeadamente que o cepticismo associado à primeira é passível de ser superado se seguirmos os ensinamentos wittgensteinianos embora isso não aconteça no segundo caso, consistindo a minha solução para ultrapassar essa "vertigem" numa atitude epistémico-moral.

5 Remeto o leitor para os trabalhos de Schulte (2001), Wright (2007) e McDowell (2009). 


\section{Epistemologia-dobradiça}

A designação, manifestamente bizarra, de "epistemologia-dobradiça" decorre do Da Certeza, onde Wittgenstein escreve o seguinte:

Com a mesma certeza mediante a qual cremos numa qualquer proposição matemática, sabemos também como as letras "A" e "B" são pronunciadas, como se chama a cor do sangue humano, que outras pessoas têm sangue e chamam a isso "sangue". (Wittgenstein, 1974: §340)

Afirma ele então na sequência disto mesmo:

Quer dizer, as questões que colocamos e as nossas dúvidas dependem de que certas proposições estão isentas de dúvida, sendo como dobradiças [Angeln], nas quais aquelas se articulam. (Wittgenstein, 1974: §341)

E conclui o seu raciocínio enunciando mais adiante:

Mas não é mesmo assim, que não podemos precisamente investigar tudo e que, portanto, temos de nos contentar com a suposição? Se eu quiser que a porta se mexa, as dobradiças têm de estar assentes. (Wittgenstein, 1974: §343)

Habitualmente não faríamos equivaler a certeza de uma proposição matemática aos exemplos da experiência comum que Wittgenstein nos dá no $\$ 340$. Diríamos que sabermos pronunciar letras do alfabeto, identificar cores ou fazer juízos de natureza biológica constituem coisas que sabemos com uma certeza diferente daquela mediante a qual sabemos que " $5+7=$ 12". Na verdade, existem muitas pronúncias diferentes, e não por isso menos acertadas, das letras "A" e "B", tal como existem diferentes identificações cromáticas, mais ou menos gerais, e variados níveis de precisão científica. Saberá um português pronunciar melhor as letras "A" e "B" do que um alemão ou um inglês? Responderá mais adequadamente à pergunta "De que cor é o sangue humano?" alguém que diga que é vermelho do que uma pessoa que diga que é carmim ou magenta? E quem disser que as outras pessoas não são robôs mas têm sangue a correr-lhes nas veias saberá menos do que quem contraponha que aquilo que lhes corre nas veias é um conjunto de células em suspensão num líquido chamado plasma? $\mathrm{O}$ que Wittgenstein pretende, todavia, é apontar para a naturalidade com que sabemos tudo isso, independentemente da acuidade que se possa considerar. Estas são daquelas coisas que, normalmente, nem nos passa pela cabeça que sabemos, tal é o enraizamento que têm nas nossas práticas quotidianas. Se alguém nos perguntar "Sabes como se pronunciam as letras 
'A' e 'B'?", "Sabes de que cor é o sangue humano?" ou "Sabes que os seres humanos têm sangue?", isso parecerá tão evidente que dará a sensação de que nunca foi por nós autenticamente aprendido. E esse é o ponto fundamental para Wittgenstein: que as nossas certezas mais profundas não foram alvo de uma aprendizagem, mas foram sendo assimiladas no âmbito da nossa acção ${ }^{6}$. Mais importante ainda, tais assimilações revestem-se de um tão elevado grau de rotatividade - enquanto aquilo que faz girar - que não parece ser possível pô-las em causa.

Ora, é esta evidência imediata e indispensável que determinados conhecimentos assumem na nossa vida que está no cerne da noção de "epistemologia-dobradiça", sendo as proposições que expressam esse fundo denominadas "proposições-dobradiça". É importante notar que as "proposições-dobradiça" são extraordinariamente compactáveis já que incluem variadíssimos elementos epistémicos (nem todos eles decisivos para a compreensibilidade de cada situação), estando subsumidas em proposições empíricas comuns.

Para ilustrar o que aqui está em jogo, tomemos como exemplo a proposição "As minhas filhas nunca estiveram em Plutão". À partida, dir-se-ia que se trata de uma mera proposição empírica, mas, se atentarmos ao seu conteúdo, percebe-se que ela é mais do que informativa relativamente a certa circunstância. Que as minhas filhas nunca tenham estado em Plutão não significa algo equivalente a que as minhas filhas nunca tenham estado em Paris. Tanto quanto sei, elas nunca estiveram em nenhum desses sítios, mas a admissibilidade de cada um dos cenários é completamente diferente. Ainda que não haja nada que me leve a supor que as minhas filhas já tenham estado em Paris - porque tenho acompanhado de perto as suas vidas e sei que isso não se passou -, seria possível que elas o tivessem feito sem eu ter notícia disso. De facto, embora tenha estado com elas a maior parte do tempo, houve alturas em que me ausentei, pelo que essa possibilidade se apresentaria como concebível. "Confessamos-te, papá, fomos a Paris numa ocasião em que estiveste no estrangeiro" poderia ser uma declaração surpreendente mas não mais do que isso. Sabendo que é possível viajar para Paris em poucas horas e podendo perfeitamente substituir a narrativa que me havia sido contada originalmente por aquela que agora é tomada

6 É claro que nessa assimilação fomos sendo instruídos de alguma maneira. Acerca da oposição entre "aprender" (lernen) e "instrução" (Unterricht), veja-se Wittgenstein, 1974: $§ 179$.

7 Para além dos trabalhos de Pritchard neste domínio, são de destacar os de Coliva (2015) e Coliva \& Moyal-Sharrock (2016). 
por verdadeira ${ }^{8}$, arrumaria esse episódio na versão que tenho da história do mundo e apenas me questionaria pelo porquê de as minhas filhas me terem ocultado tal coisa. "Deveria tê-las levado à Eurodisney", cogitaria provavelmente. Suponhamos agora que aquilo que elas me diriam era: "Confessamos-te, papá, fomos a Plutão numa ocasião em que estiveste no estrangeiro". Qual seria a incredulidade que experimentaria perante tal informação! O que se passa é que "Fomos a Plutão" não tem, epistemologicamente falando, o mesmo estatuto de "Fomos a Paris". E nada neste mundo me convenceria disso. A proposição "As minhas filhas nunca estiveram em Plutão" manter-se-ia, assim, inabalável, estando associada - e aqui reside a sua importância epistemológica - a muitas outras proposições, por exemplo: "Nunca nenhum ser humano esteve em Plutão", "Seria extraordinariamente demorado e difícil viajar para Plutão", "Plutão não tem condições para a vida humana", etc.

Mas imagine-se que haveria desenvolvimentos científicos e tecnológicos capazes de pôr pessoas em Plutão. O Da Certeza contém múltiplas considerações sobre a impossibilidade de os seres humanos irem à Lua e sabemos que poucos anos depois foi possível fazer tal coisa ${ }^{9}$. Isto demonstra que o exemplo plutónico é, afinal, de natureza empírica, tendo aquilo que se sabe acerca do assunto sido aprendido. Para alguém que não tenha o mínimo conhecimento de astronomia, Plutão nem sequer existirá. Veja-se, aliás, o que Wittgenstein diz:

Aquilo em que acreditamos depende daquilo que aprendemos. Todos acreditamos que é impossível ir à Lua; mas poderia haver gente que acreditasse que era possível e que acontecesse às vezes. Dizemos: estes não sabem muita coisa que nós sabemos. E, ainda que possam estar certos da sua causa - estão errados e sabemo-lo.

Se compararmos o nosso sistema de saber [System des Wissens] com o deles, o deles apresenta-se como muito pior. (Wittgenstein, 1974: §286)

Poderíamos dizer de igual modo que, se compararmos o nosso sistema de saber com aquele que Wittgenstein tinha, o qual the permitiu fazer a afirmação supracitada, o dele apresenta-se como muito pior. Estaria ele ainda assim cego para os avanços da ciência a ponto de pensar que ir à Lua seria mesmo impossível? Ou foram os seus exemplos concebidos precisamente para dar conta de eventuais mudanças paradigmáticas,

8 Sobre os processos de acomodação daquilo que tomamos por verdadeiro, veja-se Venturinha, 2015.

9 Cf. Wittgenstein, 1974: $\S \S 106,111,117,171,226,238,269,286,327,337,338,661$, 662 e 667. 
para falar em termos kuhnianos? A proposição "Nunca ninguém foi a Plutão" expressa algo que, neste momento, não é contestável, servindo de dobradiça ou de eixo a todas as proposições que envolvam esse planeta anão (qualificativo que, diga-se, apenas entrou no vocabulário científico há poucos anos). Quando Wittgenstein refere no §341 que “as questões que colocamos e as nossas dúvidas dependem de que certas proposições estão isentas de dúvida”, ele está justamente a indicar que proposições como "É possível que as minhas filhas tenham ido a Plutão" ou "Talvez eu próprio já tenha estado em Plutão e não me lembre” não fazem qualquer sentido.

\section{Compromissos-dobradiça a-racionais}

O carácter empírico ou evolutivo deste tipo de crenças não se enquadra, porém, naquilo que Pritchard entende ser a manifestação mais concreta da "epistemologia-dobradiça", a saber, os "compromissos-dobradiça a-racionais” (2012: 258; 2016: 69, 89, 102-103, 174-175). Claramente, o que está subjacente à crença de que não é possível ir a Plutão não é algo a-racional. Para que haja um compromisso-dobradiça a-racional, temos de apelar ao nosso lado mais animal. O que poderia contar, pois, como uma "proposição-dobradiça” neste sentido? Eis algumas propostas:

$p_{1}$ - Tenho duas mãos.

$p_{2}$ - Tenho um corpo.

$p_{3}$ - Preciso de me desviar dos objectos.

$p_{4}$ - Existo há algum tempo.

O exemplo mooreano "Tenho duas mãos" parece indicar algo que sabemos sem que isso tenha sido aprendido por nós nalguma fase da nossa vida, equivalendo a qualquer coisa verdadeiramente intuitiva. Desde tenra idade que os seres humanos começam a usar as suas mãos instruindo-se a esse respeito na prática. O que está implicado em $p_{1}$ permite realizar todo um conjunto de acções sob a forma de conhecimentos derivados, e.g. sei abotoar a camisa, cortar o pão, escrever, fazer adeus, pegar num copo, etc. É óbvio que não pensamos explicitamente que sabemos que temos mãos quando levamos a cabo essas tarefas. Se por infelicidade perdêssemos uma mão ou mesmo as duas, os conhecimentos derivados seriam forçosamente actualizados em função das circunstâncias. Passaríamos a saber que podíamos fazer certas coisas e não outras, elaborando um cálculo prévio a esse respeito. É por isso que $p_{2}$ é ainda mais clara quanto à a-racionalidade 
que Pritchard advoga pois mesmo os animais irracionais têm consciência da sua corporeidade e das limitações que esta lhes confere. O seu saber que têm aquele corpo e não outro ${ }^{10}$ é o que determina que se movimentem desta ou daquela maneira, que enfrentem certos animais e não outros, etc. Isto faz ver que aquilo que se encontra em $p_{3}$ é, na verdade, uma extensão de $p_{2}$ já que tanto os animais racionais como os irracionais dependem da consciência de corporeidade para saberem movimentar-se no espaço. É por se ter um corpo que se percebe que a solidez dos outros corpos, móveis ou inertes, constitui uma obstaculização. Nesse sentido, "Se for contra aquilo, vou magoar-me” é algo que um ser humano epistemologicamente partilha com outros animais. Do mesmo modo, a consciência expressa em $p_{4}$ de que não existimos apenas há alguns instantes mas que experimentamos uma duração num mundo que nos precede é qualquer coisa de angular tanto na espécie humana como noutras espécies.

$\mathrm{O}$ que entretanto salta à vista é aquilo a que se poderia chamar $\mathrm{o}$ minimalismo desta "epistemologia-dobradiça”. Poder-se-ia efectivamente argumentar: se aquilo que importa aos epistemólogos wittgensteinianos é identificar crenças a-racionais que cães ou gatos também possuem, em que medida é que a nossa racionalidade é epistemologicamente relevante? Danièle Moyal-Sharrock sublinha precisamente a animalidade como decisiva para Wittgenstein. Explica ela:

A ideia revolucionária de Wittgenstein no Da Certeza é que aquilo a que os filósofos têm tradicionalmente chamado "crenças básicas" - aquelas crenças nas quais em última instância todo o conhecimento tem de estar baseado - não podem, sob pena de regressão infinita, ser elas próprias crenças proposicionais. Elas são realmente modos de agir de carácter animal ou irreflectido, os quais, quando formulados (e.g. por filósofos), parecem crenças proposicionais. É esta aparência errónea que leva os filósofos a acreditar que no fundo do pensamento está ainda mais pensamento. Pois, embora frequentemente lembrem conclusões empíricas, as certezas básicas (ou "certezas-dobradiça” ou "dobradiças” [...]) constituem o suporte não fundamentado, não proposicional do conhecimento, não o seu objecto. (Moyal-Sharrock, 2016: 24-25)

Esta visão de Moyal-Sharrock apoia-se numa declaração que Wittgenstein faz no Da Certeza, onde refere que concebe a "certeza" ou "segurança" (Sicherheit) - no sentido em que dizemos que estamos

10 A atribuição de saber aos outros animais é evidentemente problemática. Veja-se a este respeito Venturinha, 2018, sec. 3.2, onde, sendo debatida a metaforização proposta por Ernest Sosa, é introduzida a noção de “conhecimento*” na sua diferença face à versão padronizada de "conhecimento". 
certos ou seguros disto ou daquilo - "como algo que está para além do justificado e injustificado", acrescentando ele: "por assim dizer como algo animalesco [Animalisches]" (Wittgenstein, 1974: §359). Se é verdade que uma parte significativa da nossa performance epistémica acontece de forma animalesca, enquanto irreflectida, isso não significa que, nessas situações, experimentemos um vazio ao nível de processos mentais, reflexivos. Tal como Andy Hamilton afirma, "embora o conceito de Wittgenstein de certeza 'animal' seja não-racionalista, ele não advoga um irracionalismo ou um não-cognitivismo” (2014: 136). Naturalmente que se considerarmos que as nossas crenças são sempre, por mais irreflectidas que sejam, proposicionais, então temos de admitir que outros animais, ao fazerem a mesma coisa, também disporiam de tais crenças, o que seria bastante controverso. Parece, portanto, que a posição de Moyal-Sharrock é mais defensável uma vez que admitirmos "o animal em epistemologia” será menos polémico do que admitirmos a epistemologia no animal. Mas as alternativas não são assim tão lineares.

Dado que um exame adequado desta matéria excede o âmbito deste artigo, limitar-me-ei a fazer duas considerações. Uma tem a ver com o minimalismo já referido. Se a epistemologia, qua "epistemologia-dobradiça”, tiver como propósito identificar aquelas atitudes epistémicas mais básicas, mais irreflectidas, que se traduzem num "saber como" prático, então o seu propósito não será muito diferente do de qualquer psicologia animal. Ora, isso é manifestamente pouco de um ponto de vista epistemológico. Aquilo que torna a "epistemologia-dobradiça” interessante é, precisamente, a relação indissociável em nós do animal, do irreflectido, com o racional. A outra consideração que quero fazer, em conexão com esta, diz respeito àquilo que Pritchard entende por "compromissos-dobradiça superlativos”, que se articulam em "proposições-dobradiça superlativas” (Pritchard, 2012: 267-268, 271; 2016: 95-102, 105-106, 109, 173-174, 204, 206; 2018b: passim). Um determinado über hinge commitment expressar-se-á em über hinge propositions no eixo das quais rodarão todas aquelas que não forem über. Pritchard especifica estas noções acrescentando a ideia de pessoalidade. Escreve ele:

[...] podemos distinguir, por um lado, entre o compromisso-dobradiça superlativo que qualquer pessoa tem e, por outro, os modos muito diferentes nos quais este compromisso-dobradiça superlativo se manifesta em compromissos-dobradiça em relação a proposições específicas quando se trata de pessoas particulares (dentro de culturas específicas, épocas, etc.). Chame-se a estes últimos compromissos compromissos-dobradiça pessoais e chame-se às proposições sancionadas pelo compromisso-dobradiça pessoal as proposições-dobradiça pessoais. (Pritchard, 2016: 95-96) 
Aquilo que Pritchard procura é um modelo explicativo para a mutabilidade das nossas crenças mais voláteis, o que, enfatiza ele, não acontece com o "compromisso-dobradiça superlativo" já que este "claramente não é algo que possa mudar ao longo do tempo" (ibid.: 96). No quadro deste modelo, não haverá razões para falarmos de relativismo ontológico, como se nada estivesse estabelecido. Há, sim, variadíssimas formas mediante as quais aquilo que é mais fundante, superlativo, se pode desdobrar ${ }^{11}$. Que a proposição "Não se pode ir à Lua" fosse para Wittgenstein uma "proposição-dobradiça" e que a proposição "É possível ir à Lua" o seja para esta comunidade a que pertencemos não demostra que tudo é possível. O que isto demostra é, entre outras coisas, a necessidade que temos de alguma definição acerca daquilo para o qual estamos despertos. Com efeito, faz parte do nosso "compromisso-dobradiça superlativo" a organização da experiência em compartimentos epistemológicos, aos quais está associado um maior ou menor nível de aprofundamento, não sendo possível uma indiferença tout court. É claro que somos indiferentes relativamente a muitas coisas, mas somo-lo porque não o somos relativamente a muitas outras. Sabemos que se pode ir à Lua ou que não se pode ir a Plutão porque dispomos de algumas informações que nos instruíram nesse sentido, embora somente os especialistas na matéria saibam dar explicações pormenorizadas em relação ao facto de isso ser assim. Para a maioria das pessoas, constituem compartimentos epistemológicos bem mais importantes aqueles que dizem directamente respeito às suas vidas quotidianas - o compartimento da sua percepção ou o da sua memória, por exemplo, aos quais se ligam complexos mecanismos de convicção e de crença sob a forma de "proposições-dobradiça superlativas". Nada mudaria nas nossas vidas se fôssemos informados de que doravante a (até agora) dobradiça epistémica "Não se pode ir a Plutão" seria inválida. O nosso acreditar que isso era impossível, havendo dados suficientemente credíveis que apontassem noutro sentido, sofreria meramente um processo de revisão. Mas muito nos espantaria se fossem levantadas dúvidas concernentes à veracidade daquilo que temos perante ou do que nos recordamos vivamente.

11 Não é por acaso que vários filósofos estão presentemente a usar o conceito wittgensteiniano de "dobradiça" em diversas áreas da epistemologia. Veja-se a este propósito Venturinha, 2019. 


\section{Compromissos-dobradiça anticépticos}

Retomemos neste contexto $p_{1}$ - "Tenho duas mãos" - e procuremos imaginar o que se traduziria em $\neg p_{1}$. Consideremos uma situação em que $\mathrm{N}$ acorda num hospital depois de ter sofrido um acidente de viação e ser induzido em coma. Ainda confuso, $\mathrm{N}$ procura certificar-se de que não perdeu nenhum membro. Por alguns instantes, $\mathrm{N}$ não sabe se - i.e. não está seguro de que - tem duas mãos. É isto uma instância de $\neg p_{1}$ ? Seria mais propriamente algo que poderíamos expressar através da notação usada em lógica modal "é possível que..." aplicada a $p_{1}, v i z$. $\forall p_{1}$ ou, dado que a situação é dubitativa, $\downarrow \neg \mathrm{p}_{1}$. A hesitação quanto a escrever $\checkmark p_{1}$ ou $\diamond \neg p_{1}$ revela bem o carácter basilar de $p_{1}$ que não está, de facto, a ser imediatamente posta em causa. O que importa sublinhar é que numa situação como esta faria sentido que $\mathrm{N}$ duvidasse (até certo ponto) de que tinha duas mãos ou outro membro do corpo pela simples razão de que podia efectivamente ter sido alvo de alguma amputação.

Mas o que sucederia se, neste momento, alguém me perguntasse se eu estava realmente certo daquilo que é expresso por $p_{1}$ ? Introduzamos a notação da lógica epistémica para dar conta disto mesmo, de que este agente que sou $(a)$ tem conhecimento $(C)$ de que tem duas mãos $(\chi)$, viz. $C_{a} \chi$. O que me levaria a considerar $\neg C_{a} \chi$ ? É preciso compreender que a inteligibilidade de $C_{a} \chi$ depende, com efeito, da ponderação de que, ainda que remotamente, $\neg C_{a} \chi$ podia ser o caso. Logo, tanto $C_{a} \chi$ como $\neg C_{a} \chi$ têm de ser logicamente admissíveis. Contudo, o que se passa tanto com $C_{a} \chi$ como com $\neg C_{a} \chi$ é que, ao contrário de outros casos, não há flexibilidade lógica ${ }^{12}$. Quer dizer, $C_{a} \chi$ apresenta-se como de tal forma fundante que, a exemplo das tautologias tractarianas, que eram sinnlos, parece não dizer nada. E naturalmente que, nesta ordem de ideias, $\neg C_{a} \chi$ assemelha-se às contradições tractarianas, que também eram sinnlos e não diziam nada. $\mathrm{Ou}$ seja, $C_{a} \chi \mathrm{e} \neg C_{a} \chi$ não acrescentam ou retiram verdadeiramente coisa alguma à cognoscibilidade da situação. Assim, se $a$ tem conhecimento que $\chi$, então $a$ não pode ter conhecimento que $\chi$ não é o caso, correspondendo isto ao seguinte axioma:

$$
C_{a} \chi \rightarrow \neg C_{a} \neg \chi
$$

12 Um exemplo simples dessa flexibilidade será que o agente $(a)$ tem conhecimento $(C)$ de que existe uma disciplina chamada lógica $(\lambda)$, de tal modo que $C_{a} \lambda$ só é pensável por relação à possibilidade de $\neg \mathrm{C}_{a} \lambda$, já que $a$ poderia ter conhecimento de muitas coisas que não fossem $\lambda$. 
Outra forma de dar conta do que está aqui implicado é, no âmbito desta reflexão, usar o chamado princípio $K K$, ou $C C$ na nossa língua, i.e. o ter conhecimento de que se conhece ${ }^{13}$. O que este axioma enuncia é que se $a$ tem conhecimento que $\chi$, então $a$ tem conhecimento de que $a$ tem conhecimento que $\chi$ :

$$
C_{a} \chi \rightarrow C_{a} C_{a} \chi
$$

O princípio revela problemas que têm sido apontados por diversos autores, entre eles Timothy Williamson. Diferentemente daqueles que salientam que crianças ou animais não dispõem da reflexividade que é própria do princípio $C C$, se bem que conheçam de alguma maneira ${ }^{14}$, Williamson introduz o problema da "inexactidão" para rejeitar esse princípio. O que ele sustenta é que, mesmo que reflictamos sobre a nossa situação epistémica e que julguemos ter conhecimento do que conhecemos, esse reconhecimento pode ainda ser inexacto. Explica Williamson:

[...] o falhanço do princípio $C C$ é uma consequência natural da inexactidão do nosso conhecimento do nosso conhecimento. Pelo metaprincípio da margem de erro, o conhecimento do nosso conhecimento é governado por um princípio de margem de erro, de onde se segue que o princípio $C C$ é falso. (Williamson, 1994: 228)

Especifica ele que esse falhanço "é esperado não apenas porque não somos perfeitamente reflexivos, mas porque, ainda que sejamos reflexivos, as nossas capacidades cognitivas não são perfeitamente precisas" (ibid.: 230). Regressemos ao nosso exemplo "Tenho duas mãos" para ilustrar o problema que Williamson levanta. Ainda que nada me leve neste momento a pôr isso em questão, observo as minhas mãos a escrever no teclado do computador e penso que não tomei nenhuma medicação que me fizesse duvidar das aptidões visuais ou reflexivas que me reconheço ter. Tudo me levaria, portanto, a subscrever o princípio CC. Mas posso eliminar liminarmente que não estou a sonhar, que não estou, ainda que involuntariamente, sob a influência de alguma substância ou que não sou um simples cérebro numa cuba que tem a ilusão de que tem duas mãos, que tem um corpo, que tem de se desviar dos objectos e que existe há vários anos? Diria, evidentemente, que continuo a saber tudo isso. Mas,

13 Note-se que na maior parte do tempo não estamos despertos para esse conhecimento de primeira ordem, ou seja, não temos conhecimento de segunda ordem disso mesmo, tão imersos estamos nos contextos epistémicos em que nos encontramos.

14 Veja-se a título de exemplo Dretske, 2004: 176. 
quando o cepticismo deflagra, há, de uma maneira mais problemática do que noutras situações, nomeadamente de índole perceptiva ou memorativa, inevitavelmente que ponderar alguma "margem de erro". A consideração de um outro nível de "compromisso-dobradiça" proposto por Pritchard é aqui pertinente. Enuncia ele:

Existe uma terceira categoria de compromisso-dobradiça que temos de demarcar entre compromissos-dobradiça pessoais e compromissos-dobradiça superlativos, a qual concerne à nossa atitude para com cenários cépticos radicais. Chame-se a estes compromissos-dobradiça anticépticos e chame-se às proposições sancionadas pelo compromisso-dobradiça anticéptico as proposições-dobradiça anticépticas. Claramente, em virtude de se ter o compromisso-dobradiça superlativo, é-se levado por isso a considerar esses cenários como falsos. (Pritchard 2016: 97)

O que é que poderia ser, nos termos de Pritchard, uma "proposição-dobradiça anticéptica" capaz de revelar o fundo a que estamos vinculados - o "compromisso-dobradiça superlativo"? A proposição "É evidente que tenho duas mãos quando as observo" constituiria um bom exemplo, correspondendo a uma mera extensão de $p_{1}$. De acordo com Williamson, "o conhecimento, e apenas o conhecimento, constitui evidência", o que resulta numa equação que denomina por " $E=C$ " (2000: 185 ; cf. também 193). Williamson parece estar aqui a adoptar um infalibilismo ${ }^{15}$, mas em face da "inexactidão", ou "vagueza" 16 , que identifica, não parece admissível equalizar a evidência de que tenho duas mãos com o conhecimento disso, de tal maneira que isso seja compreendido como necessariamente assim. Recorrendo mais uma vez à notação da lógica modal, $\square p_{1}$ é evidente mas não infalível. E o mesmo acontece, mutatis mutandis, com $\square p_{2}$, $\square p_{3}$ e $\square p_{4}$. É neste quadro que se torna pertinente analisar as noções de "angústia epistémica" e "vertigem epistémica" propostas por Pritchard.

\section{Conclusão: angústia epistémica e vertigem epistémica}

Ainda que Pritchard entenda que a argumentação wittgensteiniana é suficiente para ultrapassar a "angústia epistémica" posta pelos cenários cépticos, ele não considera que o problema possa desaparecer por completo. Esclarece ele:

15 Veja-se neste sentido Brown, 2018: 4.

16 Cf. Williamson 1994: 6 et passim. 
[...] existe um inevitável vestígio psicológico de dúvida céptica que permanece mesmo depois de a solução ter sido alcançada (embora não algo que esteja agora a acompanhar uma genuína angústia epistémica acerca da nossa situação epistémica).

Chamo a esse estado psicológico vertigem epistémica [...]. (2016: 6)

Aquilo que se passa é que, atendendo à lógica que funda o nosso posicionamento no mundo, somos capazes de afastar dúvidas radicais identificando a sua incoerência. Vimos como certos compromissos não deixam de funcionar mesmo quando somos confrontados com desconfianças relativamente a algo que tomaríamos normalmente por evidente. Mas isso não significa que "o entendimento de Wittgenstein da estrutura de avaliação racional" ou "da estrutura das razões" (Pritchard, 2012: 259, 262-263; 2016: 73-74, 77, 87-88, 102-103, 114, 149, 200; 2018a: 78, 80, 82) consiga fazer eclipsar um desconforto epistémico que, quando é sentido, nos coloca perante uma fragilidade incontornável. Continuamos a realizar as nossas tarefas mundanas, obedecendo às crenças mais básicas que temos, mas não conseguimos afastar um resquício de cepticismo. Afinal de contas, poderíamos estar a sonhar ou sob o efeito de alguma substância que nos alterasse a reflexividade ou inclusive ser meros cérebros numa cuba. Trata-se, efectivamente, de uma incerteza mínima racionalmente justificável. Esta passagem é clara quanto a isso:

A vertigem, acima de tudo, é uma fobia, mas tem nas suas raízes uma base racional, pese embora o próprio medo não seja racionalmente fundamentado e reconhecido enquanto tal. (Boult \& Pritchard, 2013: 33)

Esta clausura epistémica a que estamos votados, não podendo ser inteiramente ultrapassada de um ponto de vista teórico, é, na verdade, ultrapassável num âmbito prático, não tanto por via do pragmatismo em que estamos já absortos quotidianamente mas sobretudo se adoptarmos uma perspectiva moral. Qual é o rationale desta proposta ${ }^{17}$ ? Que quando estão em jogo questões morais, digam-nos elas mais ou menos directamente respeito, a posição que temos relativamente aos indivíduos e instâncias envolvidos nunca deixa margem para quaisquer vertigens epistémicas, tal é o nosso comprometimento, ou compromisso, com o que se está a passar ${ }^{18}$. Ninguém que se veja confrontado com um dilema moral - por exemplo, contar o que se fez a outrem porque se acredita que isso é aquilo que se

17 Uma exposição inicial encontra-se em Venturinha (2018: 7.4, 11.3, 12.1).

18 Isto não equivale a assumir uma posição que esteja vinculada a alguma epistemologia moral. Veja-se a este respeito Venturinha, 2016. 
deve fazer - ponderará sequer por breves instantes a possibilidade de $\neg p_{1}$, etc. O plano moral convoca-nos inevitavelmente para a acção e, sem exigir justificações epistémicas de qualquer índole, não se deixa bloquear por nenhum subterfúgio da razão teórica.

\section{Referências bibliográficas}

Boult, Cameron \& Pritchard, Duncan (2013), "Wittgensteinian Anti-Scepticism and Epistemic Vertigo", Philosophia, 41, pp. 27-35.

Brown, Jessica (2018), Fallibilism: Evidence and Knowledge, Oxford: Oxford University Press.

Coliva, Annalisa (2015), Extended Rationality: A Hinge Epistemology, Basingstoke: Palgrave Macmillan.

Coliva, Annalisa \& Moyal-Sharrock, Danièle (eds.) (2016), Hinge Epistemology, Leiden: Brill.

Dretske, Fred (2004), “Externalism and Modest Contextualism”, Erkenntnis, 61, pp. 173-186.

Hamilton, Andy (2014), Routledge Philosophy Guidebook to Wittgenstein and On Certainty, London: Routledge.

McDowell, John (2009), “Wittgenstein’s Quietism”, Common Knowledge, 15.3, pp. 365-372.

Moyal-Sharrock, Danièle (2016), “The Animal in Epistemology: Wittgenstein's Enactivist Solution to the Problem of Regress”, in Coliva, Annalisa \& Moyal-Sharrock, Danièle (eds), Hinge epistemology, Leiden: Brill, pp. 24$-47$.

Pritchard, Duncan (2012), "Wittgenstein and the Groundlessness of Our Believing”, Synthese, 189, pp. 255-272.

Pritchard, Duncan (2016), Epistemic Angst: Radical Skepticism and the Groundlessness of Our Believing, Princeton: Princeton University Press.

Pritchard, Duncan (2018a), "Epistemic Angst”, Philosophy and Phenomenological Research, 96.1, pp. 70-90.

Pritchard, Duncan (2018b), "Wittgensteinian Hinge Epistemology and Deep Disagreement”, Topoi, https://doi.org/10.1007/s112450189612y

Schulte, Joachim (2001), "Wittgenstein's Quietism”, in Meixner, Uwe (ed.), Metaphysics in the Post-Metaphysical Age, Vienna: öbv\&hpt, pp. 37-50.

Venturinha, Nuno (2010), "A Re-Evaluation of the Philosophical Investigations", in Venturinha, Nuno (ed.), Wittgenstein After His Nachlass, Basingstoke: Palgrave Macmillan, pp. 143-156.

Venturinha, Nuno (2015), “The Epistemic Value of Holding for True”, Journal of Philosophical Research, 40, pp. 155-170.

Venturinha, Nuno (2016), "Moral Epistemology, Interpersonal Indeterminacy and Enactivism", in Padilla Gálvez, Jesús (ed.), Action, Decision-Making and Forms of Life, Berlin: Walter de Gruyter, pp. 109-120. 
Venturinha, Nuno (2018), Description of Situations: An Essay in Contextualist Epistemology, Cham: Springer.

Venturinha, Nuno (2019), “Wittgenstein and Applied Epistemology”, Wittgenstein-Studien, 10, pp. 147-151.

Williamson, Timothy (1994), Vagueness, London: Routledge.

Williamson, Timothy (2000), Knowledge and Its Limits, Oxford: Oxford University Press.

Wittgenstein, Ludwig (1974), Über Gewißheit / On Certainty, ed. G. E. M. Anscombe \& G. H. von Wright, tr. Denis Paul \& G. E. M. Anscombe, Oxford: Blackwell.

Wright, Crispin (2007), “Rule-following without Reasons: Wittgenstein’s Quietism and the Constitutive Question”, in Preston, John (ed.), Wittgenstein and Reason, Ratio, 20.4, pp. 481-502.

\title{
RESUMO
}

Este artigo explora temas centrais da epistemologia de Duncan Pritchard intimamente relacionados com a ideia wittgensteiniana de uma "epistemologia-dobradiça”. A primeira secção chama a atenção para o carácter eminentemente empírico das nossas "dobradiças". A segunda secção incide sobre a noção de Pritchard de "compromissos-dobradiça a-racionais", mais especificamente a sua distinção entre o par "compromissos-dobradiça superlativos"/"proposições-dobradiça superlativas" e o par "compromissos-dobradiça pessoais"/"proposições-dobradiça pessoais". A terceira secção traz para a discussão a compreensão de Timothy Williamson de "conhecimento inexacto" e examina um outro par de noções introduzidas por Pritchard, a saber "compromissos-dobradiça anticépticos”/“proposições-dobradiça anticépticas”. Concluo com uma reavaliação do diagnóstico feito por Pritchard de que, confrontados com um cenário céptico, a nossa "angústia epistémica" pode ser ultrapassada se seguirmos os ensinamentos de Wittgenstein no Da Certeza acerca da "estrutura de avaliação racional”, mas que uma "vertigem epistémica" nunca pode ser em última instância eliminada. O meu argumento é o de que num cenário moral não existe lugar para vertigem.

Palavras-chave: Duncan Pritchard - Cepticismo - Epistemologia-dobradiça Ludwig Wittgenstein - Vertigem epistémica

\begin{abstract}
This paper explores central themes of Duncan Pritchard's epistemology intimately related to the Wittgensteinian idea of a "hinge epistemology". The first section calls attention to the eminently empirical character of our "hinges". The
\end{abstract}


second section focuses on Pritchard's notion of "arational hinge commitments", more specifically his distinction between the pair "über hinge commitments"/“über hinge propositions" and the pair "personal hinge commitments"/"personal hinge propositions". The third section brings to the discussion Timothy Williamson's view of "inexact knowledge" and examines another pair of notions introduced by Pritchard, namely "anti-skeptical hinge commitments"/“anti-skeptical hinge propositions". I conclude with a re-evaluation of the diagnosis made by Pritchard that, confronted with a sceptical scenario, our "epistemic angst" can be surpassed if we follow Wittgenstein's teaching in On Certainty about the "structure of rational evaluation", but that an "epistemic vertigo" can never be ultimately dispelled. My argument is that in a moral scenario there is no room for vertigo.

Keywords: Duncan Pritchard - Epistemic vertigo - Hinge epistemology - Ludwig Wittgenstein - Scepticism 